\title{
An Interpretivist Case Study of a South African Rural Multi-Purpose Community Centre
}

\author{
Jean-Paul Van Belle \\ University of Cape Town $<$ jvbelle@,commerce.uct.ac.za $>$ \\ Jonathan Trusler \\ University of Cape Town $<$ jon@wpf.co.za $>$
}

\begin{abstract}
This article presents an in-depth case study analysis of a single rural telecentre located in the Western Cape Province of South Africa. The study embraces the sociotechnical research paradigm and uses a combination of hermeneutics and actor-network theory as the theoretical foundation with which to explore the mutual interaction between people and ICTs. The objective of the analysis is to gain a much deeper and richer understanding of the implementation issues of a multi-purpose community centre in a rural development situation.
\end{abstract}

\section{Context}

There is an increasing focus on the growing disparity between the involvement of developed and developing societies in the new "information age". ICTs are often seen as being the critical link to bridge this gap (Chapman 2002). An ICT initiative that has been receiving increasing attention is that of the telecentre, and the related concept of the multi-purpose community centre (MPCC). The South African government is strongly promoting the diffusion of these MPCCs throughout the country, particularly in rural areas. However, successful MPCC initiatives are still few and far between (Burton 2000). As Benjamin (2000) notes, "while there is much talk in international conferences of them, there are not many successful [telecentres] in developing countries." The reasons for the failure of many of these initiatives are still not clear, despite a number of research efforts (Avgerou 1998, CINSA 2003, Montealegre 1999, Moyo 1996, Roode 2003).

A growing strand of literature in the ICTs for Development field refers to the interaction between technology and society (Brohman 1996). This approach is often referred to as the socio-technical paradigm of technology. This study embraces this school of thought and actor-network theory is used as a theoretical foundation with which to explore the mutual interaction between people and machines.

This paper presents an in-depth case study analysis of a single rural telecentre in the Western Cape Province of South Africa. The concept of telecentres and MPCCs have been around for a relatively short period of time. Consequently, no solid theoretical approaches have been developed for implementing these centres. However, a number of contrasting perspectives have arisen with regards to certain key issues.

The first issue is that of success. At first glance this issue is relatively clear: Has the project achieved its goals? However, as Heeks (2002) points out, there is often considerable subjectivity involved when assessing the success and failure of development projects. Who sets the goals? For whom are the outcomes undesirable? Some authors contend that success should be seen in the light of those who fund or implement the project while other authors prefer to look at success from the perspective of the participants of a project. 
Another, related issue is that of sustainability. While some see sustainability as being determined by the financial flows of a telecentre, others include determinants such as relevancy of services, human resources, and infrastructure (Mayanja 2001).

A final issue is the role of telecentres in development. Some authors maintain that the underlying assumption of telecentres is that "appropriate information can contribute significantly to development." (Roman \& Colle 2002: 5) Other authors focus less on the information aspect and more on the enabling aspect of ICTs in their ability to support local development projects.

\section{Introduction to the Case Study}

The case under study: is the implementation of a Multi-Purpose Community Centre (MPCC) in the Dwars River Valley (DRV) of the Western Cape of South Africa. The valley is situated in a picturesque mountainous area traditionally known for its wine farms. There are a few large commercial wine farms in the valley, but the majority of the population experiences high levels of unemployment and live close to the poverty line.

An MPCC is a specific type of telecentre, or "physical space that provides public access to ICTs for educational, personal, social, and economic development" (Gomez et al. 1999). While it is difficult to find any consistency in the definitions of the terms used to describe different types of telecentres (see Colle \& Roman 1999), we will define for our purposes a MPCC as a "telecentre which has a political motivation to aid in the upliftment of a disadvantaged group."

The DRV is a name which came into existence only relatively recently in 2000 , when the six historically distinct communities in the valley united as the smaller local municipalities were absorbed into the overall Stellenbosch Municipality. The MPCC under study, the Dwars River Valley MPCC (DRV MPCC), was implemented in 2002 and 2003, after a lengthy implementation process. The process started in 1998, when the dominant community within the DRV, Pniel, applied for government funds to start a Youth Centre. When the funds were approved in 2001, the amalgamation in the valley had already taken place, and the concept of the youth centre had evolved into the concept of an MPCC. Thus, what was originally planned to be the Pniel Youth Centre eventually became the DRV MPCC which in turn was implemented with the goal of providing developmental service to the six communities of Kylemore, Johannesdal, Pniel, Lanquedoc, Banghoek, and Groot Drakenstein.

A project manager, with extensive experience in MPCCs, was brought in to manage the implementation process which was obtaining government funding from the Local Economic Development (LED) fund and the Human Settlement and Redevelopment (HSRP) fund.

The MPCC consisted of 10 computers, a printer, and a single dial-up Internet connection. Software on the computers included Windows, the Microsoft Office suite, and Microsoft Project. The centre was housed within an existing municipal building in Pniel, the most centrally located community in the valley, with plans to build a new, separate building during 2004.

The MPCC business plan was based on replication of a model developed by the project manager during other pilot projects done in conjunction with the South African Council for Scientific and Industrial Research (CSIR). The model is based on four core components, supported by ICT, as illustrated in figure 1 below. 


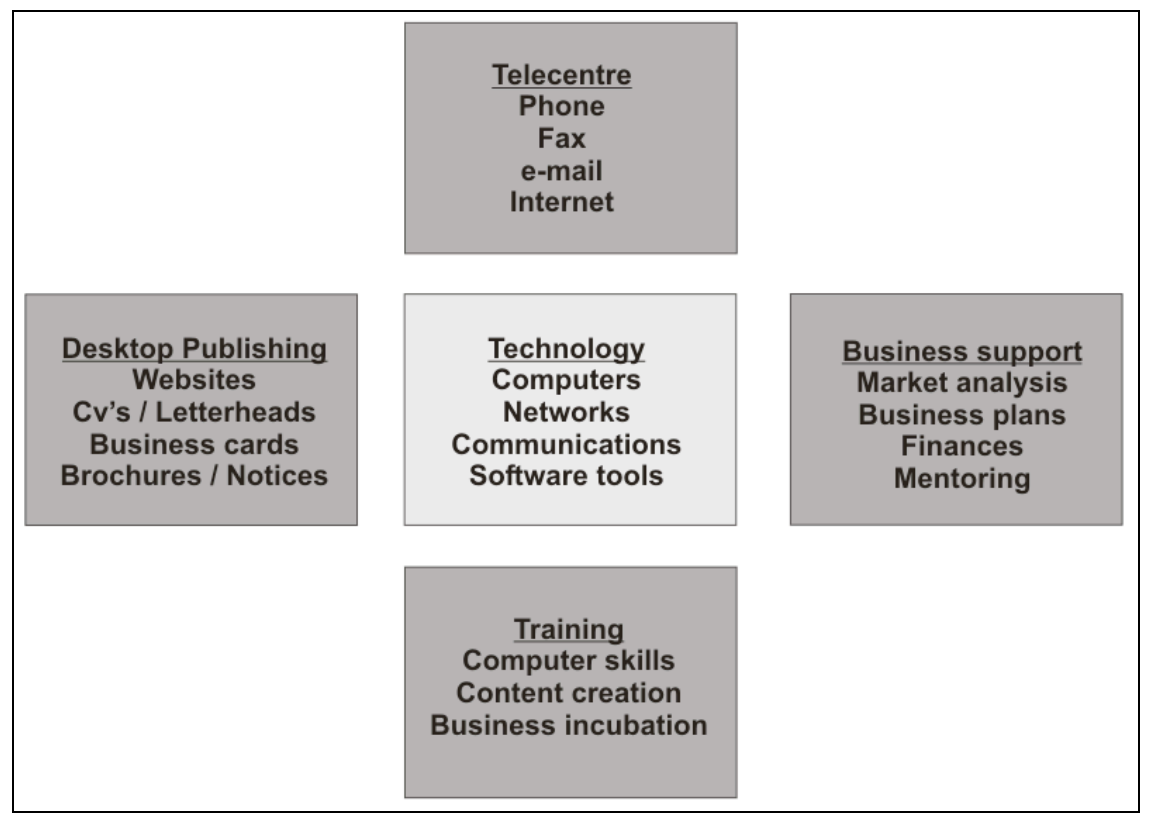

Figure 1: The Components of the MPCC Model (Source: Digimile Project Management Documentation)

The explicit aim of the MPCC when it was implemented was to foster economic development within the valley by creating spin-off projects that could use the MPCC infrastructure but would support separate entrepreneurial ventures. These ventures would contribute to the sustainability of the MPCC by paying for the services they required such as business support, desktop publishing (DTP) and so forth. The MPCC would also serve as a centre for individuals who needed training, telephony and other services.

The MPCC business plan was built around the centre eventually becoming a financially self-sustaining entity with the help of initial, start-up funding from government. It was estimated that the centre itself could provide sufficient income to support three full-time employees.

In 2002, a committee of twelve community representatives was elected to make decisions regarding the MPCC and its implementation process. The committee was ultimately responsible for the project and consisted of two representatives from each of the six communities. After an extensive consultation process supervised by the project manager, the committee decided to focus on four areas of potential benefit to the valley: tourism, water, housing and agriculture. The tourism project was the most successful resulting in a number of spin-off projects, including a successful business removing alien trees from the river bank.

Currently, the MPCC is in a state of limbo. Originally, the HSRP fund handed over a (symbolic) cheque with much fanfare and publicity with a value of $\mathrm{R}$ (and) 1,4 million (approx. \$250,000 USD). This amount was to be used to "create municipal assets". The committee thought that they could best use the money by creating assets relating to the tourism project, such as mountain huts, fishing spots on the river, and picnic areas. The HSRP however, did not agree - they wanted more tangible assets such as buildings. Eventually, as a result of disagreements the funding was withdrawn (except for R 560,000 to build a new MPCC building) and overnight the project was stranded. The new building is to be completed during 2004, but the projects and indeed the momentum for the entire initiative seems to have been lost.

\section{Research Methodology}

The main objective of this research is to explore the implementation issues of an MPCC in a rural development situation. The research approach followed is as follows. The next section, called "themes" provides an analysis of the emergent themes of the study. This section analyses the case study from different perspectives and highlights individual factors. A "Hermeneutic Spiral" is used to guide this 
analysis process, as each of the themes is examined individually. The analysis is based on the detailed study of background documentation and in-depth interviews with the many stakeholders of the MPPC.

The use of hermeneutics was inspired by Klein \& Myers (1999) who present a useful guide on how to conduct interpretive case studies in information systems and recommend hermeneutics as a valuable form of interpretivist research. The Hermeneutic Spiral can be seen as the overarching principle of hermeneutic interpretivism where:

The movement of understanding is constantly from the whole to the part and back to the whole. Our task is to extend in concentric circles the unity of the understood meaning. The harmony of all the details with the whole is the criterion of correct understanding. The failure to achieve this harmony means that understanding has failed (Gadamer 1976: 117).

The following section uses "Actor-Network Theory" to discuss the study as a whole. The aim is to build on the identified themes and provide a more systemic view by using an integrative framework. ActorNetwork Theory (ANT) is used as this theoretical framework. The strength of ANT is in its ability to describe and make sense of complex social contexts occurences. (Nandhakumar \& Vidgen 2001, Underwood 2002).

It must be noted that only one complete cycle of the Hermeneutic Spiral will be presented here. Ideally, the cycle consists of analysing parts followed by holistic reinterpretation which is to be followed by subsequent cycles of in-depth "analysis of the parts" but now informed by the holistic view.

\section{A Description of the PARTS: The EMERGING THEMES}

This section analyses the data collected and identifies the issues within emergent themes. The source materials are written documents as well as in-depth interviews with many of the stakeholders involved with the MPPC.

\section{Community Dynamics: The Power Game}

The most consistent theme which emerged from all three rounds of interviews was the importance of understanding and handling community dynamics.

There was an obvious rivalry between the dominant community of the valley, Pniel, and the most isolated, rural community, Groot Drakenstein. This rivalry was aggravated by various factors, including the perception that Pniel was always the beneficiary of "upliftment" projects. Pniel was already home to the municipal buildings, the post office, the library and the most affluent inhabitants of the valley. So when the MPCC was also situated there, it was understandable that the other communities felt somewhat aggrieved. However, Pniel is situated in the middle of the valley, on the main road making it the most accessible area and therefore it is the logical place to put an MPCC that is meant to serve the whole valley. As the project manager commented:

Now the problem that you have is that there is one prominent community, Pniel. It's on the main road, it's where the municipal offices are, it's where the more affluent people of the valley live, so they tend to look down their noses at the rest of the valley, make discouraging comments about them, according to where they live. And then the other communities comment on the 'uppitiness' of the people of Pniel.

As a result of this division between the communities, the MPCC ran into a number of problems. Many of the participants commented on people 'boycotting' the Centre simply because it was located in Pniel and not in their own community. There is a perception, as one of the participants noted that, "Pniel's people don't let people feel at home."

This antagonism towards the Centre being located in Pniel led to a number of other difficulties, most notably when it came to community participation in decision making. The project manager illustrates the difficulty with this example: 
We went to Groot Drakenstein [to set up a meeting to discuss creating a community trust] and they couldn't give us a date. When they gave us a date, they couldn't give us a venue. So we said well come to Pniel - no they're not coming to Pniel. In the end we said this meeting is for you, we'll be in Pniel. When we got to Pniel, they had shifted it to a venue in Groot Drakenstein, to the barracks there. So we went to the barracks, and then it wasn't our meeting anymore, it was their meeting - an integrated development planning meeting, and we could add our item to the agenda. And it turned into a big argument on the IDP issues, so much so that we never even got into a discussion on the trust.

As a result of these difficulties, evidently caused by a small minority of people in the Groot Drakenstein community, the whole process was almost "derailed". It is hardly surprising then that when asked the question, "How would you go about implementing an MPCC if you were given the job of project manager?" almost all respondents said that community buy-in was the most essential aspect. Municipal officials, who were responsible for establishing the initial committee, were also unanimous that "community dynamics" was the most difficult aspect when it came to implementing the MPCC. One official went so far as to say, "I can honestly tell you that (that) community - that's why they call it the Dwars River Valley - they [are] a bit 'dwars'. [T] hey try to be difficult and one can say stubborn or arrogant in some ways." ['dwars' is an Afrikaans word meaning 'across'].

In addition to these "community dynamics", there were also other more subtle issues such as mistrust and suspicion that contributed to the community being "wary" of using the MPCC. One suspicious participant commented,

They don't seem to be using the money for any of the projects but they say there is no money. So the question is, 'What happened to the money?' and they won't tell us... We have asked for the financial statements to be made available to the community but the answer we always get is:

'Where have you heard of a company making its financial statements available to the public?'

This comment was made despite the repeated claims from a number of Centre staff and municipal officials that, "we like to get the information out to the community and so we tell them what is going on our books are open."

It is difficult to make sense of these contradictory statements. One explanation is that these contradictions are the result of contrasting perspectives of the same set of facts. Another explanation is simpler: someone is lying. However, it is clear that, when it comes to community dynamics, there is a definite power struggle between competing interests, often resulting in subterfuge and hidden agendas. When these factors are not properly taken into account, events occurring in the social realm very often don't make sense.

\section{The Mpcc As A Vehicle For Economic Development}

Based on the interviews there appeared to be a distinct spectrum of understanding concerning MPCCs and their role in development among the different groups of actors.

The project manager, as could be expected, was very clear on how the MPCC operated and its role in enabling economic development in the valley. The four components of the MPCC, especially, the training and business advisory components strengthened by adding project management training, would build capacity for spin-off projects which would create economic development within the valley. The MPCC would be self-sustaining and would be able to support three full-time employees on its income.

The perspective of the municipal employees with regards to MPCCs was more political in nature. "President Thabo Mbeki himself actually started this initiative of MPCCs way back in 1997," was one comment substantiating the legitimacy of using MPCCs in communities.

Municipal employees also had a more flexible outlook as to what exactly an MPCC was supposed to be. "The beauty of the MPCC is that it's a vehicle for the community to drive up to (approach) whatever need they require from the municipality." However, another municipal employee was more displeased by the lack of clarity:

[E]verybody is talking about Multi-Purpose Community Centres, but we're not sure actually what it should look like, or how the management and operations should work. And I think that's where 
[the project manager] actually played a leading role. Because it's easy to erect a building, but it's what you do inside the building that counts. So in my opinion I think the word, MPCC is actually a generic term because no-one really knows what an MPCC is. Should it house a Post Office? Is it a payment point for pensioners? Or should it only involve a community centre that is used for different projects in the community?

Overall local municipal employees had a sense that MPCCs had some vague relationship to economic development but the dominant reason for implementing them was political: "It's being pushed by National and Provincial Government."

Participants had varying perspectives on what the MPCC was meant to achieve. Some saw it as a means to get cheap (or free) computer training and land a job. Others however, were more philosophical,

[B] fore the MPCC was here, we didn't take notice of anything around us...Now, my eyes have opened. I see quite a lot of things, a lot of opportunities...to explore. Because here was always a river but we didn't take notice of the river. Now we see that we can use it for fishing [as a tourist attraction].

Thus, to some participants the MPCC brought a new perspective, an awareness, of entrepreneurial opportunities that had not previously been identified.

Finally, there was an almost unanimous optimism that the new building would result in increased success for the MPCC. As one participant enthused:

[When we move into the new building,] we will be an MPCC alive! We will have an Internet café. The computer training will be separate and then people can come in from the morning to the afternoon and whenever it suits them. Then we will be separate from the operation - the MPCC team. And we can link better with the tourism team. And we will try to make it then a proper $M P C C$ that everyone will use.

It is important to note that the current location in the municipal building has a number of drawbacks, including limited Internet lines, and poor visibility from the outside. The new building (funded by the HSRP) would be on the main road, making it far more visible. It would also have an ISDN line, making Internet usage more economical. Even so, most actors saw the new building as the start of the 'proper' and successful MPCC. This implies rather optimistically that all the current problems could somehow be blamed on the drawbacks of the current premises.

\section{Computers Essential For Development}

When asked about the role computers played in their projects the participants generally focused on the artefacts that could be generated by computers. A typical statement would be, "to be able to...type stuff up on the computer such as business plans and CV's."

Municipal employees saw computers as a completely natural advance to be made on the road of development. There outlook was somewhat similar to that of a technophile in that computers are seen as an inevitable progression, that should occur sooner rather than later. There is the perception of an urgent need to make up the 'backlog' as illustrated in this quote from an official:

[I]f you look at industry, if you look at the business world outside, everyone wants you to work on a computer. And that's the way its going unfortunately and there is a big backlog of people not having access to these because of funds and economic problems that they have.

There appears to be a strong movement from the community and the municipality towards pursuing computers as an ends in themselves. Another municipal official noted that,

W]ithin a decade or so, people will mainly focus on computers for doing their work, so technology will play a big part. It's good that you get people involved with computers right from the start and get them acquainted with computers.

This is not surprising considering the big push from the national and provincial governments to involve computers in development projects. As was elsewhere noted, it is difficult to dispute the potential of computers in development. However, it is very dangerous to pursue technology as an end in itself, without correctly understanding its effects. 
While the participants and municipal officials tended to focus on the artefacts that could be generated by computers, the project manager was more interested in the way that computers got people to think and work in a specific way.

Most of the proposals that we see at community level, are hand-written and they don't deal with the financial aspects properly. You get rough statements of 'We think we need R 200,000' but there is no budget or anything to justify this. With the computers the people were trained to do this properly... [I]t wasn't the case of technology looking for a cause; it was a case of putting technology in there because we need it. It wasn't a direct or indirect objective to get computers into the community, it was a given that these objectives are only possible with computer technology.

For the project manager then, computers enabled people to think in a more logical, structured manner. Computers are not an end in themselves, but rather a means to aid people to, for example, "deal with financial aspects properly." The project manager was less focused on the computers producing artefacts and more focused on the processes encouraged by using computers. Put another way, it's not the project plan that is essential but rather the planning of the project.

\section{The Internet: Source of all Knowledge}

When asked about the Internet, participants were very quick to talk about the "ability to learn" about things on the Internet. A typical sequence of questions went as follows:

- Do you use the Internet?

- No.

- Would you like to?

- Yes I would like to.

- What would you use it for?

- To learn more about project management because you can do that on the Internet.

There seems to be a lack of understanding as to what exactly the Internet can and can't do for people in development situations. There is an over-optimistic attitude that 'anything you need to know' can be found on the Internet.

The project manager sums up the situation nicely:

People are very glib about what the Internet can do for communities, but their perspective is all wrong. You know 'you can get on the Internet and learn' is a glib statement that a lot of people make. You have to learn first to be able to learn on the Internet if at all.... [T] he people in the Dwars River area used email extensively... [T] hey also went into electronic banking quickly, and made payments on a monthly basis to the participants of the projects... Initially, they also used the Internet extensively, until they saw the phone bill that came with it, so now they've cut down a lot. We taught them to create websites, so they were looking at other websites to get an idea.

Perhaps it is a bit premature to draw any conclusions regarding the use of the Internet in the DRV MPCC because the Internet has not been easily accessible, with only the one line available. This lack of infrastructure has made extensive use of the Internet unfeasible. However, there are areas such as email and electronic banking which seem to have been taken up quickly and demonstrate that the Internet can be used effectively by participants. It is not yet clear if the Internet will be very useful as a tool for learning, particularly given the lack of available relevant, local content.

\section{Funding is the Trigger}

Funding was another crucial theme that emerged consistently throughout the interviews. The municipal officials were very much of the opinion that the funding should be once-off to get the project started:

There is a perception of people on the ground level that it is one of the functions of provincial and national government to plough money into projects like this. I see that in a different light. The thing must be sustainable - absolutely - the money that comes from provincial and national 
government, must be a trigger type of funding...you can't forever pump money into a bottomless pit.

One of the main problems with the funding from the participant's point of view was that while $\mathrm{R} 1,4$ million was initially promised to the project the bulk of this money was later withdrawn leaving only $\mathrm{R}$ 560,000 to build the new MPCC building. The project manager described the situation as follows:

Initially, it was very nice, we could jump in, use all the skills, everybody got busy on the development of the valley and got paid out of the funds. We did a hundred and ten different things, all very well, the project management skills came to the fore, the PC skills came out, the business planning skills came out, and everything worked very well, until there was a hiccough with the funding... Overnight we had no funding for the project; we had no means to pay the people who were active in the project. Massive expectations had been created in the process, and we had to motivate why people had to hang on when all of a sudden they weren't getting paid. With the result that most of the people with other obligations went and found other jobs. So we ended up with 6 people remaining, hanging in.

Several valid reasons were given for the withdrawal of the funding including that the funding was given on the basis of an older proposal and the scope of the project had changed since that proposal; and that the HSRP fund is set up specifically to fund infrastructure projects where tangible municipal assets are created. In the case of the DRV, the money was being used for less tangible outcomes, the so-called 'soft' issues rather than 'hard' projects. However, the project manager was quick to point out that,

It's nobody's fault, government was fully entitled to say that you've changed the scope and we're taking away the funding...problems started before the funding became an issue...the withdrawal of the funding just magnified all of the problems that were already there and were being revealed before the funding issue came.

Thus, we see that although the sudden withdrawal of funding did seem to interrupt the momentum of the project, it can't be identified as the main reason for the difficulties encountered. The following two themes emerged mainly from the perspective of the project manager, but seem to add significantly to our understanding of the process of implementing ICTs in development projects.

\section{A Confusion of Roles}

Throughout the project there was continuous uncertainty with regard to responsibilities and roles. There was never a centre manager and so this role was automatically filled by the chairperson of the committee. The municipality already had an official who worked in the valley and his job description was extended to be an 'overseer' of the project. However, none of these people got paid for what they were doing, because, no-one knew who was ultimately responsible. According to one municipal official:

The one thing that we are not sure of is - and province couldn't give us guidance, was the payment of such a centre manager. Would they fund it or would it be the responsibility of the municipality? And they made it clear that it was our responsibility. You see it's a new post and if it's not on your organigram you can't just go and create a new post.

And so the crucial position of centre manager went unfilled. However, the problem went beyond finding funding to pay someone to fill this position - as well there didn't seem to be any local person capable of filling the position.

And so a lot of responsibility suddenly shifted to the project manager. Although he came from outside the community, he was soon seen as an essential part of the project. There was enormous respect for him from most of the participants as well as from the municipal officials. He was often described as the 'expert' but was also seen as a friend of the community. As one participant noted, "[He] can get in his car now and drive down to my sister's house and he will be welcome." The following description of his role comes from a municipal employee:

I think [the project manager] was the driver of this whole thing. I'll tell you why... [H] saw the potential of the Dwars River Valley itself and he's been preaching that to the different sides, to the tourism side, to the economic development side, the business sphere, and a lot of things. But a part from that, [he] has a passion for the valley, and that is a driving force in itself... [H]e's the type of 
guy that you can go a couple of miles with... [H]e's committed, apart from you know he gets his salary from here, but apart from that, you know he's here in the valley trying to trigger this whole thing - to motivate the guys.

However, the strength of the project manager, and his ability to lead, seemed to become a pseudosatisfier as it nullified the emergence of any strong local project leaders. After all, the explicit role of the project manager was to hand over the project to local people once they had been trained sufficiently to run the centre on their own. One of the participants described the situation well:

[The project manager] was the driver. [He] was the one who stepped on toes. [He] was the one who told you, 'I want that thing, and I want it now, not yesterday, now!' He is the one that pulled everything together. If he was not here then everything would fall apart. Not that we are not in control, everyone knows what they have to do in here. But he is the one, not with the ideas, we all have ideas, but he is the one that puts the action to the ideas and makes sure that things get done.

Thus, while the participants were continuously involved in every aspect, they never had to take responsibility for anything because they knew they had the project manager to fall back on. They knew that he would "make sure that things got done."

The project manager became the central actor responsible for everything from submitting monthly municipal reports on the project, to managing operations, to securing funding from a number of sources. This leads us on to the final theme, the "passive / active" struggle.

\title{
The Passive / Active Struggle
}

The major theme that came out of the reflections of the project manager was the struggle he underwent to get the attitude of the participants to change from being passive to being active. Participants can either be active or passive depending on the type of implementation approach that is undertaken. Top-down approaches usually lead to participants being passive, while bottom-up approaches somehow create active participants. This does not seem to have been the result achieved in this case. Significant time was spent on community facilitation, and participants were given every opportunity to drive the project in a bottom-up manner. Yet, this was not enough to create active participants. The frustration of the project manager is clear when he says,

\begin{abstract}
It just comes out as an attitude where, as a trainer in that situation, I have difficulty with instilling an entrepreneurial spirit because the entrepreneurial spirit just isn't there. You get to the point where you think that it can't be put there, even as much as you try, because you try harder and harder, but maybe somebody is born with entrepreneurial spirit, and you can can't put it there through training. People like following instructions. They like the comfort zone of knowing how much they are going to earn for a specific task. They would prefer...somebody else taking responsibility for generating the income and then taking part of that. And that is also the reason for the failure of some of the components of the MPCC, and into the project itself too, where they expected the project manager to maintain the momentum, not realising that the responsibility is actually theirs.
\end{abstract}

This struggle forms the crux of the issue. Even if everything else went according to plan, this one underlying aspect could have (or would have) caused the project to fail. And according to the project manager, "You can't hope to start addressing social issues of that magnitude in a project of this nature. Where do you start?"

In the discussion above, Interpretive Hermeneutics was used to draw out seven themes from the data under study. The focus has been on describing and understanding each of the themes individually within the overall context of the study. The following section continues the hermeneutic spiral by using actornetwork theory to form a coherent explanation of the whole (Gadamer 1976: 117).

\section{An Actor-Network Theory-based interpretation of the case study}




\section{Introduction To Actor-Network Theory}

ANT can be used in at least two different modes. It is either a framework, providing a series of tricks to aid our understanding, or a meta-theory, allowing the researcher to compare other theories or even eras (Latour 1999). In this section ANT is used in the former sense, "a framework providing a series of tricks to aid our understanding".

A peculiarity of ANT is that it is totally neutral with regards to human and non-human actants in a network. Thus, one of ANT's greatest contributions is that it allows researchers to see the world as it is experienced every day: a combination of the natural and the social. This "lens" focuses our attention on relationships and underlying mechanisms which affect networked actants. According to Monteiro (1999),

[A]llowing oneself not to distinguish a priori between social and technical elements of a sociotechnical web encourages a detailed description of the concrete mechanisms at work which glue the network together — without being distracted by the means, technical or non-technical, of actually achieving this.

ANT is based on a number of key concepts. These can be found in Callon (1986) and Atkinson (2002). The key concepts used in ANT are the following:

- Actor / Actant: have interests, and try to convince other actors so as to create an alignment of the other actors' interests with their own interests.

- The actor-network is a dynamic set of relations in which actants continually influence each other.

- Translation is the creation of an actor-network. This process consists of four major stages: problematisation, interessement, enrolment, and mobilisation.

- Problematisation: the focal actant defines identities and interests of other actors that are consistent with its own interests.

- Interessement: actions by which the focal actant attempts to impose and stabilise the identity of the other actors it defines through its problematisation.

- Enrolment: when actants accept the roles defined for them by the focal actant.

- $\quad$ The Obligatory Point of Passage (OPP): a situation that has to occur in order for all the actors to satisfy the interests that have been attributed to them by the focal actor

- Mobilisation: involves maintaining commitment to a cause of action and the OPP

\section{The Case Discussion: a Description of the Whole}

The first stage in many ANT descriptions involves an identification of the network under study. ANT does not prescribe how this network is identified, or at least constrained. By their nature, actor-networks are infinite - each actant is related to many other actants inside and outside of the area of study. This is often used as a criticism of ANT: the researcher has to use their subjective judgment (bias) to determine which actants are to be included and which are to be excluded from the analysis. However, Bijker (1993 quoted in Monteiro 1999) argues that, "it is overly ambitious (or naive) to expect ANT (or any other theoretical framework for that matter) to instruct you how to separate foreground from background."

The following actants were identified in the course of this study: Project manager; The Pniel Youth Centre; The Dwars River Valley Multi-Purpose Community Centre (DRV MPCC); MPCC Replication Model; Training; Trainees: Staff; Trainees: Entrepreneurs; The Woodpeckers; Computers; Tourism project; Internet; Committee; Chairperson; Local municipality; Researcher; HSRP fund; Community facilitator; Existing municipal building; New building; Natural resources; Community; Instigators; The Attitude of Trainees.

It might be noted that for purposes of clarity it is useful to focus on a single actant, from whose vantage point we can observe the process of translation. The focal actant in this case, for the purposes of this analysis, is the project manager (PM). The PM, even though he was only enrolled some time after the 
project had begun, played the most central role in terms of translating the interests of the various other actants. He was also the dominant spokesperson for the MPCC and its related actants.

We take as our starting point for this discussion, the following statement from the PM:

I think the Dwars River Valley had the potential to be a showcase, it still has the potential to be a showcase but maybe there are some underlying difficulties that none of these interventions are addressing, and one should take congnisance of those underlying difficulties that are there, and reveal themselves when you look back at the project.

\section{The Birth Of A New Actant: The DRV MPCC}

While the local municipality loves to observe that it merely "prioritises the needs that the community identifies," the concept of the MPCC was very much pushed on to the DRV community. As one municipal official remarked, "there was significant pressure from national and provincial government to implement these centres...The concept originated from the President himself." And so the birth of a new actant occurred: the DRV MPCC. A concept which the majority of the community had not even heard about until, as one participant noted, "I saw an advertisement in the newspaper offering free training."

\section{Problematisation (An Introduction)}

The first moment of translation started before the focal actant, the PM got involved with the process. The municipality realised that a committee would have to be formed that could act as a spokesperson for the whole DRV community. Two representatives from each of the original six communities were enrolled into the committee. It was the role of this committee to oversee the process of introducing the MPCC into the existing actor-network. From that point on all new actants had to "pass through" the committee. Thus, the committee became the first OPP.

At this point in the process the municipal officials realised that neither they, nor the committee had sufficient experience or knowledge to act as the focal actant in the remaining process of translation. For this reason the PM was brought in as an expert in aligning human and non-human interests with the interests of new MPCC actants. This was an important consideration - the vast experience of the PM in the MPCC arena had led him to experience first hand that implementing an MPCCs was far more complex than just a matter of setting up the non-human infrastructure rather it was just as important to manage the interests of the humans in the context of the "non-humans" (the institutional structure).

Once the PM had passed through the first OPP (the committee) and was successfully enrolled into the network, he very quickly set up a new OPP that would allow him to conduct the rest of the translation process in his own manner. This new OPP took the form of the replication of MPCC model. This model contains best practices from previous MPCCs that were used to inscribe the operations of the new MPCC. It worked very well as an OPP because of its grounding in the lessons learnt from scores of previous MPCCs. After all, who could offer any alternative to something with so much research behind it? This new OPP gave the PM justification for almost any decision he wanted to make - he could decide how many actants to include, how to include them, what the interests of the new actant would be and so on. Thus, the PM wrested control away from the original OPP, the committee and established his (apparently) firm control over the new OPP and thus, (apparently) over the destiny of this particular actor-network.

The central tenet of the new OPP was to create an MPCC that would foster local economic development. It would be strongly entrepreneurial in nature and stress the critical importance of the MPCC in reaching financial sustainability. Thus, any actants passing through this OPP had to conform to these processes. Their interests had to align with the interests espoused in the OPP on behalf of the new MPCC as a condition of their being enrolled into the network. Among other things, the influencing the attitudes of the trainees who were to form part of the new actor-network were very important.

The literature often refers to "active participants" as opposed to "passive participants" of development. These terms are really referring to the attitudes of the participants. The active attitude can be described as being entrepreneurial, passionate, driven, and motivated to achieve. The passive attitude can be described as the opposite: dependent, risk-averse, unimaginative and unmotivated. It is clear that the PM's entrepreneurial-based OPP was very biased towards actants with an active attitude.

\section{Interessement And Enrolment (Seduction And Success)}


The process of translation continued under the guidance of the PM. A lesson from previous projects conducted by the PM taught him that "community participation and setting up the correct governance structures [were] important for the overall success of the project." In line with this a number community workshops were held to translate the interests of the community around the interests of the MPCC.

To assist in this process the PM enrolled the community facilitator (CF) as an ally. The CF was an excellent "translator" of interests. He was able to conduct a meeting with various community actants and subtly guide the discussion to whatever objective he wanted to reach, without seeming to take a dominant role or stance. This is illustrated in this quote from one of the workshops. The outcome that the PM wanted was to have a steering committee elected. The CF noted near the start of the meeting that:

[The PM] and I could stand here and say this is how it must be done. We need a six month timeframe with a steering committee. But we are not going to do that. At the same time we don't want this to stand still. We don't want everyone to wait for everyone else.

After an hour of discussing interests and strategies, a participant in the meeting suggested that a vote should be taken to elect a steering committee. The CF praised the participant for his excellent idea and the vote took place. Mission accomplished!

Thus, with the help of this skilled ally, the translation of interests was very successful. One enthusiastic community member made this comment with regard to the proposed new MPCC at the end of a particularly successful community workshop:

This is not a dream anymore. We need this thing to happen and we are working at it. We don't have a choice anymore. We have to get this to happen.

This quote beautifully illustrates how the particular person aligned her interests with that of the new actant and accepted her role as an actant in the new actor-network. She had been enrolled! However, it is important to note that many of these actants were unemployed and living on the poverty line - in short they were desperate for solutions - and thus, ready to align their interests to any actant that promised this.

As part of the enrolment process, actants had to pass through the PM's OPP (the model). The nonhuman actants such as the computers and the Internet made it in easily - they were already inscribed into the OPP. The natural resources and the tourism project also had no trouble in passing through the OPP and enrolling themselves thanks to their already close alignment with the process of enabling economic development.

The enrolment of the human actants unfortunately, was not such an easy process. The difficulty was the result of an interesting power-struggle that had arisen. As has already been noted, the OPP required trainees to have a very specific attitude - an active attitude. In order to find people with (among other criteria) the right attitudes, a recruitment and selection procedure was established. The procedure was conducted by a panel of people from the committee and the PM. A suitability score was produced for each candidate which could be seen as a measure of how closely aligned the interests of the candidate were to the interests of the MPCC (a score of 1 meant the person was an excellent candidate, and a score of 3 meant the person was not suitable for inclusion).

A power-struggle emerged around this issue between the PM and the committee. The scores were a clear indication of which candidates the PM felt should be included in the collective. The committee on the other hand had other ideas as to which candidates were to be included. The PM described the struggle as follows:

So there were a number of 3 s, people who rated 3 in the interview situation, and there was agreement in the interview situation with a panel of 3 or 4 people that this person is out, only to be overruled by...the committee, who decided no, the person is back in... You see that a specific person is not suitable, but the management put them in, for whatever reasons, they're family or they like them or whatever... So ok fine, you deal with that person in the training situation.

And so the committee managed to reassert themselves and a tension arose between the original OPP (the committee) and the new OPP (the model). This tension activated underlying issues that would surface again later in the process. 
The process of enrolment continued through the training of the selected candidates. Trainees would become either MPCC staff (content creators or business advisors) or entrepreneurs. All trainees were taught basic computer skills and were then allowed to specialise in desktop publishing, business advising, or project management. A large number of candidates were trained because previous projects had shown that betrayal often occurred at this stage: once people had new skills they were easily co-opted into other competing actor-networks.

During the process of interessement and enrolment, a minority of people from the most isolated community in the valley purposefully did not align their interests with that of the new actant. In the previous section, the PM described the process of trying to set up a meeting with these "instigators" but after a number of attempts he achieved nothing. The instigators continuously raised interference against the project and even claimed that those involved were enriching themselves illegally from project funds. Fortunately these instigators did not have enough agency to threaten the new actor-network.

On the whole, the translation process up to this point was successful. A significant sign of this success was the funding that was awarded to the project by the HSRP fund. The actants and allies of the actornetwork were starting to mobilise and the dream of creating a showcase out of the DRV MPCC seemed to be well on track. However, the PM was not completely convinced. He had begun to sense "underlying problems" with the project. Another actant had begun to make its presence felt. It was neither a human nor a non-human - it was an attitude. More specifically it was the attitude of the trainees (both staff and entrepreneurs) that started to worry the PM. This actant was increasingly moving out of alignment from the OPP set up by the PM, and thus its interests were no longer being directly linked with those of the MPCC and the PM.

\section{Mobilisation (What Went Wrong?)}

With the promise of the funding suddenly the actor-network became a black box. It started working and everything seemed to fall into place. As already mentioned, the PM describes what happened:

[I]t was very nice, we could jump in and use all the skills, everybody got busy on the development of the valley and got paid out of the funds. We did a hundred and ten different things, all very well, the project management skills came to the fore, the PC skills came out, the business planning skills came out, and everything worked very well...

One of the major beneficiaries of the creation of this MPCC black box was the tourism project actant and the entrepreneurs who were trained in the earlier stages of translation. Suddenly, the natural resources of the valley became enrolled as a fly-fishing destination, mountain walks, and picnic areas. A business (The Woodpeckers) was established to remove alien trees from the valley and then sell off the resulting wood to nearby manufacturers.

Much of this success was enabled by the ICTs within the MPCC. For example, a business plan had to be created to ensure the financial viability of the Woodpeckers. This business plan could have been handwritten, but the computers and their software, helped produce a plan that was more complete, with an extensive budget, project plan (including tasks and human resource requirements) and a strategy for selling the wood to manufacturers. Another example, of the enabling power of ICTs, was the brochure and website produced to market the valley to tourists. Suddenly thanks to ICTs, the chances of enrolling passing tourists into the activities of the valley had increased considerably.

Even though everything was working well, the PM was still heavily involved in driving the project. $\mathrm{He}$ had to continuously motivate the actants and ensure that things were done. He started facing an uphill battle - the active / passive struggle mentioned in the previous section and a symptom of the underlying problems that had been created in the earlier stages of translation.

Then suddenly a significant betrayal took place which affected the entire actor-network severely. The HSRP fund, which had until then been seen as an ally, turned against the project. The original funding that was promised was reduced by almost a million rand. As already noted, the PM describes the situation: "[O]vernight we had no funding for the project".

Suddenly the black box was opened, and actants saw that "translations had become treason." The promise of being paid for the work they were doing had disappeared and the security afforded by the funding had been lost. The PM tried various tactics to re-translate the interests of the actants. "We 
tried...saying: We've created products, take ownership of the products, start marketing the products, but this just didn't happen..." These tactics didn't work because the attitudes of the actants were not sufficiently aligned to be able to deal with this situation. The actants had been passive all along and had continuously relied on the PM to lead, guide, and take their risks for them. Is it surprising then, that when the occasion called for them to suddenly be active - they weren't able to do so?

\section{Summary Of Discussion}

The discussion started with the quote from the PM saying that this project had and still has the ability to be a showcase. However, there are underlying difficulties. What are these difficulties?

The first difficulty was the power-struggle between the committee and the PM that manifested itself in the tension between OPPs. This issue really comes down to who should be in control of the project? Clearly, this is a normative question, but it significantly influences the outcome of the project. The result of this first difficulty was that certain people were enrolled into the actor-network without having properly aligned interests. More specifically, the attitudes of some of the actants did not meet the criteria outlined in the PM's OPP.

This contributed to the second difficulty which was the active / passive struggle. How does one get the attitude of people to be an active one? As already quoted the project manager sees this as not an easy process:

It just comes out as an attitude where, as a trainer in that situation, I have difficulty with instilling an entrepreneurial spirit because the entrepreneurial spirit just isn't there... [T] hey expected the project manager to maintain the momentum, not realising that the responsibility is actually theirs.

The original goal of the project was for the project manager to hand over the project to the local people once they had been trained. Clearly, if the attitudes of the local people are passive, removing the PM would result in a very unstable network. A possible solution to this problem came from a municipal official who commented that:

One might tend to think that in the case of the Dwars River Valley, you need a local person that is committed, that can drive the process forward, that can interact with different members of the community and is not influenced by the way of thinking of any one group of people.

Having a strong local actant such as the one proposed above, could very well allow the PM to successfully hand over the project. However, this person would have to be supported by a strong actornetwork to achieve long-term sustainability. This would involve surrounding the leader with a number of "active" participants.

\section{An Afterthought: The Future?}

The project is currently in a precarious position. The remaining funding from the HSRP is being used to build a new actant - a standalone building to house the DRV MPCC. The construction of this new actant should be finished in early 2004, and many actants have already begun aligning their interests with the promise of the new building.

Is it possible that the new actant, with all its promises, will be able to change the underlying difficulties described in the previous section? Is it conceivable, for example, that the increased visibility, increased Internet access, and increased professionalism enabled by the new actant, will lead to a change in the attitudes of the centre staff. In the view of the researchers this is unlikely to happen.

\section{Final Reflections}

The interpretive paradigm was extended through the application of hermeneutics. The "hermeneutic spiral" provided an excellent method for analysing and drawing out themes from the qualitative data collected. Seven themes were identified. The actor-network theory was then applied to aid in a final description of the whole. In this way, the themes were integrated to form a coherent overall picture. The framework was a major asset in the study. The combination of interpretivism, hermeneutics, and actornetwork theory worked well. The complementary nature of the three approaches greatly aided in the exploration, investigation and understanding produced in the study. 


\section{Reflections on the Theme Analysis and ANT-Based Discussion}

What role did ICTs played in the case-study. The study highlights a pragmatic view of the role of ICTs in development. Many studies have noted that Western practices and concepts are inscribed into computers and that these are not necessarily suitable in third-world contexts. This view was not supported in this study. It was apparent that under the right conditions, the ICTs worked well enough. Participants, (even those with relatively little previous computer experience) found it easy to learn to use computers. Of course, significant training was required, but once this was completed, participants were able to produce project plans, budgets, brochures, websites and other artefacts. These artefacts were able to inscribe further processes and practices and provided real benefit in a number of situations, including for those running a business, marketing products, or managing human resources.

One cautionary point though, is the context in which the study took place. Although it was a rural area, it could not be described as truly third-world. For example, most participants understood English well; the site was located reasonably close to an urban centre and the infrastructure of the area was good.

A second point for reflection is the role of funding in development. The HSRP fund was of the opinion that development could be encouraged by building buildings. They refused to fund "soft" activities such as community facilitation or training and support projects. However, it is clear from the ANT discussion that this narrow view is very dangerous. The success of community development projects is dependent on far more than just infrastructure. An actor-network, especially a newly formed one, requires significant nurturing in order to increase the strength of its cohesion. This is not to say that community projects necessarily require continuous funding, but rather that they require holistic funding in order to foster their chances for sustainability.

An important point that emerged from the study was the active / passive struggle. This struggle seemed to be an important consideration for the long-term sustainability of the actor-network. Without "active" participants the PM was given the responsibility of being the "driver" of the project. One of the participants suggested that what was needed was a strong local actor who could take over from the PM once the actornetwork was sufficiently stable. Thus good support was provided by the study for the concept of the middle-out, local champion identified in the literature as for example:.

"Champions are transformational leaders who inspire others to transcend self-interest for a higher collective purpose." (Du Plooy 1998)

In terms of implementation issues this study provides some useful points for reflection. The replication model for instance, provided a significant OPP for the PM to enrol actants into the collective. However, this OPP was subverted somewhat by the power struggle that developed between the committee and the PM. This suggests that there are no guarantees for determining the success of the enrolment process. In actor-networks there is always the risk of subversion and betrayal.

\section{Implications}

Overall, the possibility as presented in this paper of combining an interpretive paradigm with hermeneutics and the actor-network theory points to a promising combined framework for researchers to build on. The framework is particularly suited to studies aimed at gaining a deeper understanding of sociotechnical issues in general and in particular within the arena if ICTs for development.

Another implication of the study is that there is no recipe for implementing MPCCs. A replication model is a useful instrument but should not be seen as a guarantee of success. It is important to combine experiences from previous studies with continuous learning and context-sensitive application methods.

In terms of ICTs in development, this study provides encouraging signs that ICTs can indeed be of practical use in a variety of situations, but particularly in the area of supporting entrepreneurial development projects.

Some suggested future areas of research that arise from this study are the following.

- The area of the active / passive struggle. Is it possible for example, to change the attitudes of participants to being more active in their approach? How could this be done? Should the PM deliberately try to exercise less power and control over the project in order to allow active attitudes to develop? 
- The issue of funding MPCCs. How could funding for MPCC projects be provided in a more holistic manner? Is it reasonable to expect MPCCs to be completely self-sustainable?

- The use of the research methodology for pro-active policy advice. Can ANT and hermeneutics be used in a pro-active manner to inform the planning of an MPCC implementation rather than as a strictly post-implementation review tool? 


\section{References}

Atkinson, C. J. (2002). The Multidimensional Systemic Representation of Actor Networks: Modeling Breast Cancer Treatment Decision-Making. Proceedings of the 35th Hawaii International Conference on System Sciences.

Avgerou, C. (1998). How can IT Enable Economic Growth in Developing Countries? Information Technology for Development (8), 15-28.

Benjamin, P. (2000). Telecentre 2000: Literature Review. Online at http://www.communitysa.org.za/tele2000.htm. Last accessed 12 January 2004.

Benjamin, P. (2001). Telecentres in South Africa. Online at http://www.telecentres.am/references/info/jdcbenjamin.doc. Last Accessed 14 January 2004.

Brohman, J. (1996). Popular Development: Rethinking the Theory and Practice of Development. Blackwell Publishers, Oxford.

Brown, M. M. (2002). Foreword. In Fukuda-Parr, S., Lopes, C. \& Malik, K. (2002) Eds., Capacity for Development: New Solutions to Old Problems. Earthscan Publications, London, vii-viii.

Callon, M. (1986). Some Elements of a Sociology of Translation: Domestication of the Scallops and the Fishermen of St Brieuc Bay. In Law, J. (1986) Ed., Power, Action and Belief: A New Sociology of Knowledge? Routledge, London, 196-233.

Callon, M. (1997). Actor-Network Theory: The Market Test. In Law, J. \& Hassard, J. (1998) Eds., Actor Network Theory and After. Blackwell Publishers, Oxford.

Chapman, R. \& Slaymaker, T. (2002). ICTs and Rural Development: Review of Literature, Current Interventions and Opportunities for Action (Working Paper 192). Overseas Development Institute, London.

Community Information Network for Southern Africa / CINSA (2003). Regional Conference Report: Dialogue for a Sustainable Network of Community ICT Initiatives. Johannesburg, South Africa, August 2003.

Du Plooy, N. F. (1998). Chapter 6: The Adoption and Use of Information Technology in Organizations. In An Analysis of the Human Environment for the Adoption and Use of Information Technology.

Gadamer, H-G. (1976). The Historicity of Understanding. In Connerton, P. (1976) Ed., Critical Sociology, Selected Readings. Penquin Books, Harmondsworth, 117-133.

Gomez, R., Hunt, P. \& Lamoureux, E. (1999). Telecentre Evaluation and Research: A Global Perspective. International Development Research Centre, Ottawa.

Heeks, R. (2002). Working Paper No. 11: Failure, Success and Improvisation of Information Systems Projects in Developing Countries. Development Informatics, Working Paper Series. Institute for Development Policy and Management, Manchester.

Klein, H.K. \& Myers, M.D. (1999). A Set of Principles for Conducting and Evaluating Interpretive Field Studies in Information Systems. MIS Quarterly (23:1), 67-94.

Latour, B. (1992). Where are the Missing Masses, The Sociology of Mundane Artefacts. In Bijerker, W. E. \& Law, J. (1992). Eds., Shaping Technology/Building Society: Studies in Sociotechnical Change. MIT Press, Cambridge, 255-258.

Latour, B. (1999). Pandora's Hope: Essays on the Realities of Science Studies. Harvard University Press, Cambridge, Massachusetts.

Mayanja, M. (2001). The African Community Telecentres: In Search of Sustainability. ICT for Education Programme, World Bank Institute. Online at http://www.developmentgateway.org/download/165918/In_search_of_sust telecenters_DG.doc. Last accessed 12 January 2004. 
Moyo, L. M. (1996). Information Technology Strategies for Africa's Survival in the Twenty-first Century: IT All Pervasive. Information Technology for Development (7), 17-27.

Montealegre, R. (1999). A Case for More Case Study Research in the Implementation of Information Technology in Less-Developed Countries. Information Technology for Development (8:4), 199207.

Monteiro, E. (1999). Actor-Network Theory and Information Infrastructure. In. Ciborra, C. U. et al. (1999). Eds., From Control to Adrift: The Dynamics of Corporate Information Infrastructures. Oxford University Press, Oxford, 71-82.

Nandhakumar, J. \& Vidgen, R. (2001). Due Process and the Introduction of New Technology: The Institution of Video Teleconferencing. In Russo, N. L., Fitzgerald, B. \& De Gross, J. I. (2001). Eds., Realigning Research and Practice in IS Development: The Social and Organisational Perspective. Kluwer Academic Publishers, Boston.

Roman, R. \& Colle, R. D. (2002). Working Paper No. 10: Themes and Issues in Telecentre Sustainability. Development Informatics, Working Paper Series. Institute for Development Policy and Management, Manchester.

Roode, J.D. (2003). Presentation: A Framework for Achieving Sustainable Development through ICT Interventions. University of Cape Town, 23 April 2003.

Underwood, J. (2002). A Theoretical Basis for IS? The Contribution of ANT. Australian Journal of Information Systems (9:Special Edition), 86-92. 